\title{
Assessment of Technologies for the Silent Aircraft Initiative
}

\author{
Cesare A. Hall* \\ University of Cambridge, Cambridge, England CB2 1ST, United Kingdom \\ Emily Schwartz \\ Stanford University, Stanford, California 94305 \\ and \\ James I. Hileman \\ Massachusetts Institute of Technology, Cambridge, Massachusetts 02139
}

DOI: $10.2514 / 1.43079$

\begin{abstract}
The Silent Aircraft Initiative produced an aircraft design that combined many new and novel technologies to give a solution that was predicted to be fuel-efficient as well as extremely quiet. The study presented in this paper seeks to assess the benefits and penalties of each of the proposed technologies. A method has been developed that estimates the overall change in fuel consumption and engine noise caused by modifications to an aircraft design. The method sizes a propulsion system for a specified design and determines adjustments to the cruise performance based on changes in the engine components, the installation system, and system weight. The offdesign performance is also calculated so that the noise can be estimated. The method has been applied to show what contribution each silent aircraft technology made to the overall goal of the project. It also shows the tradeoffs between noise and fuel consumption for various technologies and indicates that there are configurations that can achieve both lower fuel burn and lower engine noise. The method has been used to identify a low-risk configuration of the silent aircraft, for which a new design is presented.
\end{abstract}

\begin{tabular}{|c|c|}
\hline & Nomenclature \\
\hline$A$ & $=$ area, $\mathrm{m}^{2}$ \\
\hline$D$ & $=\operatorname{drag}, \mathrm{kN}$ \\
\hline$d$ & diameter, $\mathrm{m}$ \\
\hline $\begin{array}{l}H, H^{*} \\
H^{* *}\end{array}$ & $\begin{array}{l}=\text { boundary-layer shape, kinetic energy, and density } \\
\text { factors }\end{array}$ \\
\hline$L$ & $=$ lift, $\mathrm{kN}$ \\
\hline $\mathrm{LCV}$ & $=$ lower calorific value of fuel, $\mathrm{kJ} / \mathrm{kg}$ \\
\hline$l$ & $=$ length, $\mathrm{m}$ \\
\hline M & $=$ Mach number \\
\hline MTOW & $=$ maximum takeoff weight, $\mathrm{kg}$ or $\mathrm{lb}$ \\
\hline$\dot{m}$ & $=$ engine mass flow rate, $\mathrm{kg} / \mathrm{s}$ \\
\hline$n$ & $=$ number \\
\hline OEW & $=$ operating empty weight, $\mathrm{kg}$ or $\mathrm{lb}$ \\
\hline PR & pressure recovery \\
\hline$p$ & pressure, $\mathrm{kPa}$ \\
\hline$S$ & $=$ wetted area, $\mathrm{m}^{2}$ \\
\hline$s$ & $=$ range, $\mathrm{km}$ \\
\hline$s$ & $=$ entropy, $\mathrm{kJ} / \mathrm{kg} \mathrm{K}$ \\
\hline$T$ & $=$ temperature, $\mathrm{K}$ \\
\hline$U$ & $=$ blade speed, $\mathrm{m} / \mathrm{s}$ \\
\hline$V$ & flow velocity, $\mathrm{m} / \mathrm{s}$ \\
\hline$W$ & aircraft weight parameter, $\mathrm{kg}$ \\
\hline$X_{N}$ & $=$ net thrust, $\mathrm{kN}$ \\
\hline$\alpha$ & $=$ aircraft climb angle \\
\hline$\eta$ & $=$ efficiency \\
\hline$\theta$ & $=$ boundary-layer momentum thickness \\
\hline$\omega$ & $=$ variable density factor (a function of jet velocity) \\
\hline
\end{tabular}

Presented at the 18th ISABE conference, Beijing, China, 2-7 September 2007; received 3 February 2009; revision received 27 May 2009; accepted for publication 21 July 2009. Copyright $@ 2009$ by the Cambridge-MIT Institute. Published by the American Institute of Aeronautics and Astronautics, Inc., with permission. Copies of this paper may be made for personal or internal use, on condition that the copier pay the $\$ 10.00$ per-copy fee to the Copyright Clearance Center, Inc., 222 Rosewood Drive, Danvers, MA 01923; include the code 0748-4658/09 and \$10.00 in correspondence with the CCC.

*University Lecturer, Department of Engineering, Whittle Laboratory. Member AIAA.

${ }^{\dagger}$ Ph.D. Student, 496 Lomita Mall

*Principal Research Engineer, Gas Turbine Laboratory, Department of Aeronautics and Astronautics. Member AIAA.

$\begin{array}{ll}\text { Subscripts } & \\ \mathrm{cr} & =\text { cruise } \\ \mathrm{emb} & =\text { embedded } \\ \mathrm{ex} & =\text { exhaust } \\ f & =\text { fan } \\ \text { in } & =\text { inlet } \\ j & =\text { jet } \\ \mathrm{nac} & =\text { nacelle } \\ \text { noz } & =\text { nozzle } \\ p & =\text { polytropic } \\ \text { pay } & =\text { payload } \\ \mathrm{pr} & =\text { propulsive } \\ \mathrm{ref} & =\text { reference } \\ \mathrm{TOC} & =\text { top of climb } \\ \mathrm{TO} & =\text { takeoff } \\ 0 & =\text { stagnation condition } \\ \infty, a & =\text { freestream, atmospheric }\end{array}$

\section{Introduction}

$\mathbf{T}$ HE demand for aircraft to be both quieter and more fuelefficient is greater than ever. The expected increase in air traffic means that the number of aircraft operations are rising continuously, leading to both greater noise and greater emissions of pollutants. Industry and government have developed the Advisory Council for Aeronautics Research in Europe 2020 vision for air transport [1]. This has the ambitious target of cutting both noise emission and fuel consumption of aircraft to one-half of the levels from aircraft built in 2000 by the year 2020. Such levels of reduction are expected to require major technological breakthroughs in both engine and airframe design.

The goal of the Silent Aircraft Initiative was to design a viable concept aircraft that is no louder than background noise in a typical urban environment. For this project, aircraft noise emission was the primary design variable. However, it was realized early in the project that to produce a credible aircraft design for the future, the fuel consumption of the design would be critical. The project has thus generated many ideas for possible new technologies that in combination have the potential to significantly reduce both noise and fuel consumption. Many of these technologies were incorporated into the final design of the aircraft, which is shown in Fig. 1. 


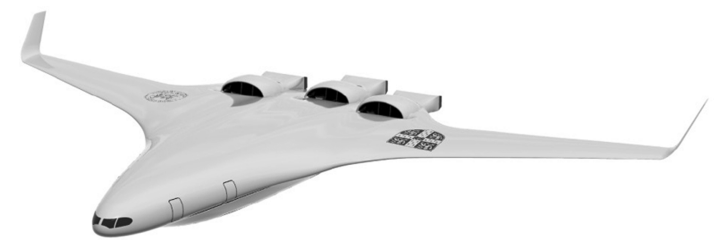

Fig. 1 Silent Aircraft Initiative final design concept (SAX-40) []].

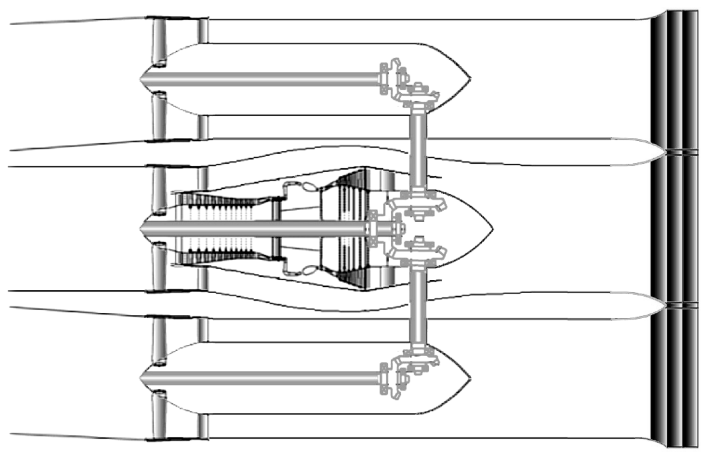

Fig. 2 Silent aircraft propulsion system [12].

The predicted noise level for the silent aircraft design pictured in Fig. 1 is $63 \mathrm{dBA}$ at the perimeter of a typical airport, as detailed in [2] ]. This noise level is close to the background noise level within a wellpopulated area. A fuel burn of 124 passenger miles per gallon was calculated, which is better than that achieved by a Toyota Prius Hybrid car carrying two people (see [3]). However, many design challenges and technical barriers were identified in the silent aircraft design, and it was recognized that without significant development work, industry would perceive such a configuration as high-risk because it includes many novel technologies. In particular, the proposed propulsion system design, as shown in Fig. 2, features boundary-layer ingestion (BLI), distributed fans, axial-radial compressors, a new transmission system, and variable-area exhaust nozzles.

The study reported in this paper was initiated to determine the impact that each of the proposed silent aircraft technologies has on the noise and fuel burn of the final design. Assessing the noise and fuel consumption impact of a technology is a complex task because an aircraft design is highly integrated and all of the systems are strongly interdependent. The aircraft fuel consumption depends on all of the engine components, the engine installation, the airframe aerodynamics, and the total aircraft weight. The noise of an aircraft consists of multiple sources that depend on many factors, including the offdesign performance and the way in which the aircraft is operated.

The method developed for this study simulates the interacting factors that influence the fuel burn and engine noise emission of an aircraft. For any new technology or change in configuration, the method determines the difference in aircraft performance that would be achieved if the aircraft were to be redesigned using the new technology. The engine is resized, the aircraft weight is adjusted, and the block fuel increment is calculated. The offdesign operation of the aircraft and engine are also determined so that the key noise sources can be estimated.

The method is first applied to a study of the design tradeoffs that exist between noise and fuel consumption for various configurations of engine and installation. It is then used to assess each of the silent aircraft technologies, and the results of progressively adding the new technologies into a conventional aircraft design are presented. The results show the relative benefits and penalties that can be expected of each technology. The findings from this technology assessment are used to identify the key features of a reduced-risk version of the silent aircraft with fewer new technologies. A detailed design of this aircraft configuration is presented and compared with the final silent aircraft concept, SAX-40 (Fig. 1).

This paper is relevant to researchers with an interest in future technology and in the overall performance and noise of aircraft. The approach used in the assessment method is new, particularly in how it accounts for the various factors affecting fuel consumption, and the results presented give new insight into the impact of various technologies. Overall, the paper aims to make a contribution toward the prioritization of future aircraft technologies and to the performance analysis of engines operating within novel installations.

\section{Method}

The overall technology assessment method described in this paper is outlined in Fig. 3. There are essentially three modules: the engine sizing, the fuel burn estimation, and the noise estimation. This section describes the models used in each of these modules and explains how they are combined to produce a result.

Note that the method only aims to determine the changes in noise and fuel burn that would be achieved relative to a conventional reference aircraft for which the overall performance characteristics

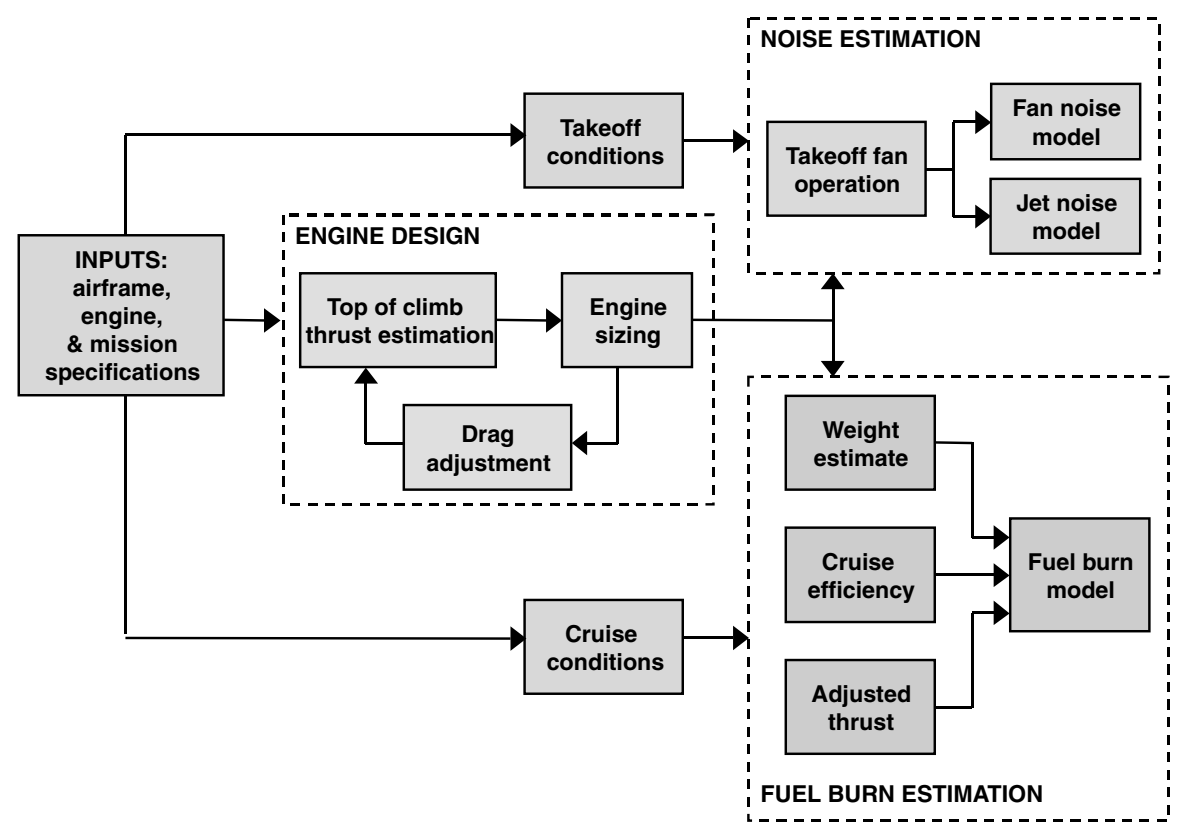

Fig. 3 Overview of the technology assessment method. 
are already known. Absolute levels are not required and this means that many of the calculations can be relatively straightforward. In addition, the method is only applicable to propulsion systems using high-bypass-ratio turbofans.

\section{A. Engine Sizing and Thrust Requirement}

This part of the method determines the engine size required for a given airframe and engine installation. The top-of-climb operating condition is the most aerodynamically demanding point for the engines, and thus the fan diameter needed for the engines is determined by the thrust required at this condition. However, as well as determining the engine thrust, the fan diameter also affects the aircraft drag because it influences the size of the engine installation. Therefore, an iterative procedure is required to find a compatible fan diameter. The overall force balance for an aircraft at top of climb, resolved in the direction of flight, can be written as follows:

$$
X_{N, \mathrm{TOC}}=0.98 g \operatorname{MTOW}\left(\frac{1}{(L / D)_{\mathrm{ref}}}+\sin \left(\alpha_{\mathrm{TOC}}\right)\right)+\Delta D_{\mathrm{nac}}-D_{\mathrm{BLI}}
$$

In this equation it is assumed that at top of climb, the aircraft weight is $98 \%$ of the maximum takeoff weight (MTOW), $(L / D)_{\text {ref }}$ is the liftto-drag ratio of the reference aircraft, $\Delta D_{\text {nac }}$ represents the change in installation drag that is caused by a change in the engine size or style of installation, and $D_{\mathrm{BLI}}$ is the airframe drag reduction that results when BLI is employed. The force balance in Eq. (1) assumes a control volume for the engine that extends from upstream of the aircraft in the freestream to downstream of the engine, where the static pressure is atmospheric. This definition of control volume is applicable to all styles of engine installation and it is pictured in Fig. 4 for the case of an aircraft with BLI.

The momentum equation can be applied to the control volume shown in Fig. 4 to give an equation for the engine net thrust in terms of the flow Mach numbers, the fan pressure ratio (FPR), and the area of the propulsive jet, $A_{j}$ :

$$
\begin{aligned}
& \frac{X_{N}}{A_{j} p_{a}}=\frac{\dot{m}}{A_{j} p_{a}}\left(V_{j}-V_{\infty}\right) \\
& \quad=\gamma M_{j}^{2}\left(1-\frac{M_{\infty}}{M_{j}}\left(\frac{1+\frac{\gamma-1}{2} M_{\infty}^{2}}{1+\frac{\gamma-1}{2} M_{j}^{2}}\right)^{-\frac{1}{2}}\left(\operatorname{FPR}^{(\gamma-1) / \gamma \eta_{\mathrm{fp}}}+\frac{\Delta T_{0}}{T_{0 \infty}}\right)^{-\frac{1}{2}}\right)
\end{aligned}
$$

In deriving Eq. (2) it is assumed that the pressure forces on the top and bottom of the control volume do not produce a net force in the flight direction. The thermodynamic effect of the engine core is modeled simply as a stagnation rise in the flow, $\Delta T_{0}$. This is an acceptable simplification for high-bypass-ratio turbofans (also see [4]). The Mach number of the propulsive jet and the FPR are related via the following equation:

$$
\mathrm{FPR}=\frac{1}{\mathrm{PR}_{\mathrm{in}} \mathrm{PR}_{\mathrm{ex}}}\left(\frac{1+\frac{\gamma-1}{2} M_{j}^{2}}{1+\frac{\gamma-1}{2} M_{\infty}^{2}}\right)^{\frac{\gamma}{\gamma-1}}
$$

This equation requires the stagnation pressure losses at inlet and exit from the engine fan, $\mathrm{PR}_{\mathrm{in}}=p_{02} / p_{0 \infty}$ and $\mathrm{PR}_{\mathrm{ex}}=p_{0 j} /$ $\left(\mathrm{FPR} \times p_{02}\right)$. The jet area given by solving Eqs. (2) and (3) can be related to the fan diameter by applying continuity between the fan inlet, Eq. (2), and the exhaust jet $j$ :

$$
\left.\frac{A_{j}}{A_{f}}=\frac{\sqrt{\operatorname{FPR}^{(\gamma-1) / \gamma \eta_{\mathrm{fp}}}+\frac{\Delta T_{0}}{T_{0 \infty}}}}{M_{2}} \frac{1+\frac{\gamma-1}{2} M_{2}^{2}}{M_{j}}\right)^{-\frac{1}{2}\left(\frac{\gamma+1}{\gamma-1}\right)}
$$

Once the total fan area is known, $A_{f}$, the fan diameter is computed from the following equation:

$$
d_{f}=\sqrt{\frac{4 A_{f}}{n_{f} \pi\left(1-\mathrm{HTR}^{2}\right)}}
$$

where HTR is the hub-to-tip radius ratio of the fan.

The engine sizing module essentially solves the set of simultaneous equations. (1- $\underline{5})$. It proceeds by using Eq. (1) to determine the thrust required for an initial guess of the fan diameter; then, by solving Eqs. (2-5), an updated fan diameter is calculated. This process is repeated until a fan diameter is found that balances the equations. The main input to the method is the FPR at top of climb, hereafter referred to as the design FPR, which is the principal design variable for a turbofan. The other inputs include the pressure recoveries, fan efficiency, and hub-to-tip ratio, which are determined based on typical values for the technology being applied. The output of the module includes the fan diameter, the top-of-climb net thrust, and the installation parameters.

\section{Estimating the Nacelle Drag}

To calculate the net thrust in Eq. (1), the portion of the aircraft's parasitic drag due to the engine nacelles needs to be estimated. This can be done using Shevell's formula [5]:

$$
D_{\text {nac }}=K S_{\text {nac }} \rho_{1} V_{1}^{2}
$$

In the preceding nacelle drag equation, $K$ is the pressure drag correction coefficient and $S_{\text {nac }}$ is the nacelle wetted-area increase relative to the bare airframe. This method can be used for various types of installation: podded (pod), BLI, and boundary-layer diverting (BLD). Figure 5 shows schematics for the three types of engine installation, and these are used to estimate the nacelle areas given in Eq. (7):

$$
\begin{aligned}
& S_{\text {nac,pod }}=n_{f} \pi d_{f} l_{\text {nac }}+2 \delta l_{\text {eng }} \\
& S_{\text {nac,BLI }}=\left(1+\frac{l_{\mathrm{ex}}}{l_{\mathrm{nac}}}\right)\left(\frac{\pi}{2}-1\right) d_{f} l_{\mathrm{nac}} \\
& S_{\mathrm{nac}, \mathrm{BLD}}=\left(1+\frac{l_{\mathrm{ex}}}{l_{\mathrm{nac}}}\right)\left(\frac{\pi}{2}-1+\frac{n_{f}}{n_{\mathrm{eng}}}\right) d_{f} l_{\mathrm{nac}} \\
& +2 \delta \sqrt{\left(\frac{d_{f} n_{f}}{2 n_{\mathrm{eng}}}\right)^{2}+\left(l_{\mathrm{nac}}-l_{\mathrm{ex}}\right)^{2}}
\end{aligned}
$$

\section{Estimating the Drag Reduction Due to BLI}

For podded and BLD engines, the ingested drag $D_{\mathrm{BLI}}$ is zero. For BLI engines, $D_{\mathrm{BLI}}$ is the drag that the airframe boundary layer at station 1 in Fig. 4 would produce if it was brought to atmospheric pressure. The following estimation of this drag, as derived in [6] , can be found by applying the boundary-layer momentum integral equation between stations (1) and $j$ :

$$
D_{\mathrm{BLI}}=\rho_{1}^{2} V_{1}^{2} \theta_{1}\left(\frac{V_{1}}{V_{\infty}}\right)^{2+H} d_{f} n_{f}
$$

The momentum deficit in the flow represented by $D_{\text {BLI }}$ has to be swallowed by the engines, and this has a negative impact on the engine performance. The total pressure loss from the freestream $(\infty)$ to station (1) can be computed using the following approximation:

$$
\frac{p_{01}}{p_{0 \infty}} \cong 1-\frac{\rho_{1}^{2} V_{1}^{3} \theta_{1} d_{f} n_{f}}{\dot{m} p_{01}} \frac{H_{1}^{*}+H_{1}^{* *}}{2}
$$

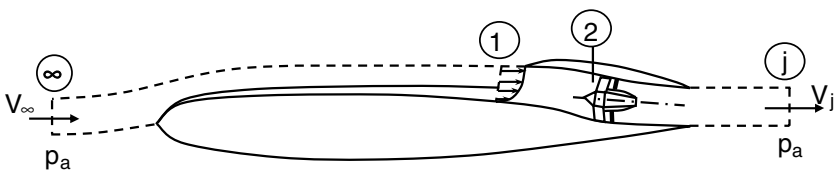

Fig. 4 Station numbering and control volume used for propulsion system analysis. 


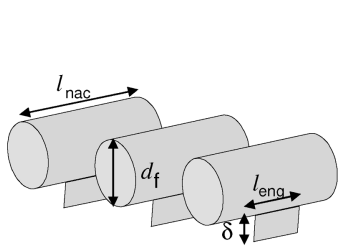

a) Podded configuration

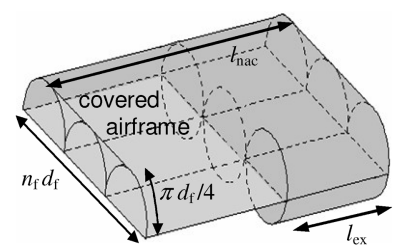

b) Embedded configuration with BLI

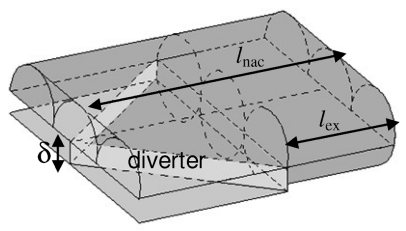

c) Embedded configuration with BLD

Fig. 5 Simplified nacelle geometries used for surface area estimation.

The boundary-layer parameters required for Eqs. (8) and (9) can be extracted from detailed computations of the airframe aerodynamics or approximated from flat-plate characteristics. Equations (8) and (9) influence the thrust generated by the engine via Eqs. (1) and (3), respectively. On one hand, the reduced airframe drag from BLI reduces the thrust requirement and therefore the fan diameter. On the other hand, the engine needs to be larger because the ingested flow includes the boundary-layer blockage. The total pressure loss calculated in Eq. (9) reduces the fan inlet pressure recovery because $\mathrm{PR}_{\mathrm{in}}=p_{02} / p_{01} \times p_{01} / p_{0 \infty}$. This increases the fan size for a given thrust and, as shown in the next section, reduces the engine efficiency.

\section{B. Fuel Burn Estimation}

The fuel burn module determines changes in the block fuel consumption of an aircraft due to the incorporation of a new technology or a change in engine configuration. The main part of the module performs calculations that are aimed at determining the overall efficiency of the engines. Another set of calculations is used to calculate changes in weight due to differences in the engine configuration. The efficiency and weight changes are then combined to give a fuel burn difference using a suitable form of the Breguet range equation.

\section{Estimating Engine Overall Efficiency}

The overall efficiency $\eta_{o}$ is the ratio of useful work done on the aircraft to the total energy released from burning fuel [7]. It can be expressed as the product of the engine thermal and propulsive efficiencies:

$$
\eta_{o}=\frac{X_{N} V_{\infty}}{\dot{m}_{\text {fuel }} \mathrm{LCV}}=\eta_{\mathrm{th}} \eta_{\mathrm{pr}}
$$

For the control volume given in Fig. 4, for a uniform jet, the propulsive efficiency is straightforward to obtain:

$$
\eta_{\mathrm{pr}}=\frac{2 V_{\infty}}{V_{\infty}+V_{j}}=\frac{2 M_{\infty}}{M_{\infty}+M_{j} \sqrt{\frac{T_{j}}{T_{a}}}}
$$

In Eq. (11) the jet Mach number can be found from the FPR at the cruise operating point using Eq. (3), and the jet temperature is determined using compressible flow relations and the stagnation temperature difference across the engine. In contrast, the thermal efficiency is quite complicated to determine. The thermal efficiency relates the change in kinetic energy of the flow that passes through the engine control volume to the energy available in the fuel. Following a thermodynamic analysis similar to that shown in [8], the thermal efficiency can be written in terms of the engine core efficiency, lowpressure turbine efficiency, and bypass efficiency:

$$
\eta_{\text {th }}=\frac{\Delta K E_{\text {total }}}{\dot{m}_{\text {fuel }} \mathrm{LCV}}=\frac{\dot{m}\left(V_{j}^{2}-V_{\infty}^{2}\right)}{\dot{m}_{\text {fuel }} \mathrm{LCV}}=\eta_{\text {core }}\left(\frac{1+\mathrm{BPR}}{1+\mathrm{BPR} /\left(\eta_{\mathrm{byp}} \eta_{\mathrm{LPT}}\right)}\right)
$$

The low-pressure turbine efficiency $\eta_{\text {LPT }}$ depends only on the turbine performance, and a typical value is used (around $90 \%$ for a modern turbofan). However, the bypass efficiency $\eta_{\text {byp }}$ is different from fan efficiency and its value has a significant impact on the thermal efficiency. It relates the kinetic energy change of the flow through the entire bypass system to the power input to the fan and, as shown in Appendix A, it is given by

$$
\eta_{\text {byp }}=1-\frac{T_{a}}{T_{01}}\left[\frac{1-\eta_{f}}{\operatorname{FPR}^{(\gamma-1) / \gamma}}+\frac{\ln \left(\mathrm{PR}_{\mathrm{in}} \mathrm{PR}_{\mathrm{ex}}\right) \eta_{f}(\gamma-1) / \gamma}{\mathrm{FPR}^{(\gamma-1) / \gamma}-1}\right]
$$

Equation (13) is plotted in Fig. 6 as a function of the total installation pressure recovery, $\mathrm{PR}=\mathrm{PR}_{\mathrm{in}} \mathrm{PR}_{\mathrm{ex}}$. It shows that total pressure losses in an engine installation have an increasingly detrimental effect on the bypass efficiency as the FPR is reduced. This is expected because the total pressure loss in the installation will represent a larger portion of the fan pressure rise. Low design FPR is applied in turbofans to give low jet velocity and therefore high propulsive efficiency and low noise. However, Fig. $\underline{6}$ indicates that a low design FPR will lead to poor performance if combined with an engine installation that has significant total pressure losses.

The fan isentropic efficiency $\eta_{f}$ is a critical factor in determining the overall fuel consumption of a turbofan and a single input value is insufficient for the method. The fan characteristic map from [4] was used to determine the fan efficiency variation. Including the fan map in the method enables offdesign engine operation to be simulated accurately, and this is particularly important for modeling fans with variable-area exhaust nozzles (Sec. III).

The engine core efficiency in Eq. (12) is determined by the engine thermodynamic cycle. For the reference aircraft, GasTurb [9], a commercial cycle-modeling method, is used to calculate the core efficiency. To determine the impact of core technology improvements, such as increased component efficiency or higher turbine inlet temperature, a simple thermodynamic cycle calculation for the core is applied, as can be found in [7]. The effect of core component Reynolds numbers on the core efficiency is also included in the method using a simple scaling relationship applied to the component polytropic efficiencies:

$$
\eta_{p}=\eta_{p, \text { tec }}\left(\sqrt{\frac{X_{N} / n_{\text {eng }}}{\left(X_{N} / n_{\text {eng }}\right)_{\text {ref }}}}\right)^{k_{R e}}
$$

where $\eta_{p \text {,tec }}$ is the component polytropic efficiency of a reference component for the technology level of interest. The Reynolds scaling constant $k_{R e}$ is taken to be 0.03 . Equation (14) uses the assumption

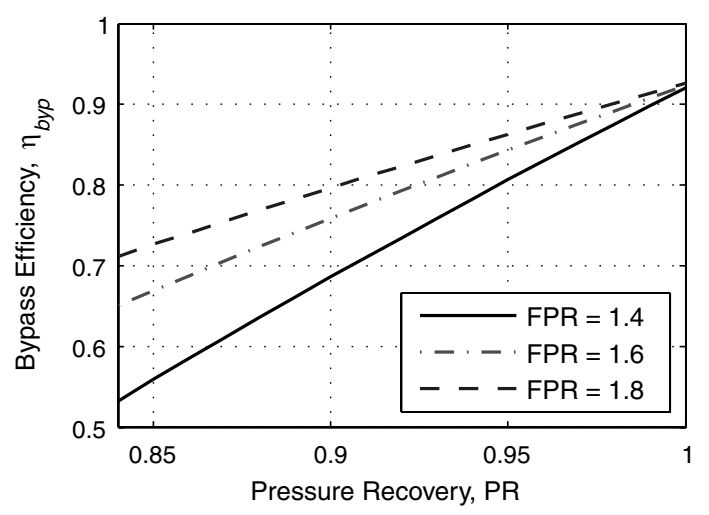

Fig. 6 Variation in the bypass efficiency with installation losses and FPR $\left(M_{\infty}=0.85\right.$ and $\left.\eta_{f}=0.9\right)$. 
that for a given flight condition, the net thrust produced by an engine is proportional to the engine cross-sectional area.

To assess the accuracy of the cruise efficiency calculations, a series of engine designs were computed in GasTurb as well as using the method described here. The results are presented in Fig. 7, which shows that the absolute differences are small $(\sim 0.5 \%)$ and that the changes between designs are, in general, accurately reproduced.

\section{Estimating Changes in Aircraft Empty Weight}

For most of the technologies of interest to this study, any changes in aircraft weight are due to changes in the engine and installation. Thus, the overall effect on operating empty weight (OEW) is found using the following:

$$
\Delta \mathrm{OEW}=\Delta W_{\text {eng }}+n_{\text {eng }}\left(\Delta W_{\text {nac }}+\Delta W_{\text {noz }}\right)
$$

The bare engine weight $W_{\text {eng }}$ does not rise as the cube of the engine fan diameter, as might be expected, due to the hollowness of parts, such as the fan containment, which has a mass proportional to the casing circumference. The following simple equation for bare engine weight variation is found to fit reasonably well to available data:

$$
\frac{\Delta W_{\text {eng }}}{W_{\text {eng,ref }}}=k_{\text {tec }}\left(\frac{d_{f}^{2.4} n_{f}}{d_{f, \text { ref }}^{2.4} n_{f, \text { ref }}}-1\right)
$$

In this equation, $k_{\text {tec }}$ is a factor that accounts for changes in the weight of a bare engine of a given size based on the configuration adopted. For example, the reference conventional three-spool engine is allotted a $k_{\text {tec }}$ of 1.0, and two-spool geared fan engines have a $k_{\text {tec }}$ of 0.89 . These values are based on engine weight assessments obtained from previous detailed engine designs described in [10].

The weight of the engine nacelle is estimated differently for podded and embedded engines, according to the following relationships from Raymer [11]:

For a podded engine,

$$
W_{\text {nac }}=k_{\text {pod }}\left(l_{\text {nac }}-l_{\text {noz }}\right)^{0.1}\left(d_{f} \frac{n_{f}}{n_{\text {eng }}}\right)^{0.294} W_{\text {eng }}^{0.611} S_{\text {nac }}^{0.224}
$$

For an embedded engine,

$$
W_{\mathrm{nac}}=k_{\mathrm{emb}}\left(l_{\mathrm{nac}}-l_{\mathrm{noz}}\right)^{0.643}\left(d_{f} \frac{n_{f}}{n_{\mathrm{eng}}}\right)
$$

In the preceding equations, the coefficients $k_{\text {pod }}$ and $k_{\text {emb }}$ can be determined from empirical relationships for installation design, as given in [11]. The exhaust nozzle weight was estimated based on unpublished data for a variable-area exhaust nozzle used in a military engine. The weight was scaled with the engine diameter, but because military exhausts operate with higher jet temperatures and velocities, this was expected to lead to a conservative (heavy) estimate. Further details on the engine component weights for the silent aircraft can be found in [12].

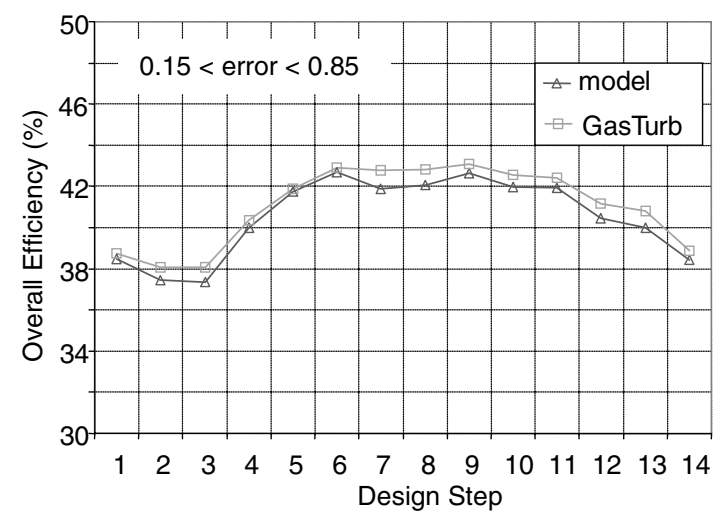

Fig. 7 Difference in overall efficiency computed with the technology assessment model and GasTurb [9].
To verify the engine weight model, results from applying Eqs. (1517) were compared with data for 20 existing engines from [13]. The model was found to match the data well, with a maximum error of less than $600 \mathrm{~kg}$.

\section{Overall Fuel Burn Adjustment}

New technologies and changes in engine configuration impact the fuel burned via a change in the aircraft weight, a difference in overall efficiency, or an adjustment to the airframe lift-to-drag ratio. The most convenient and computationally efficient way to combine these factors to give an overall fuel burn increment involves the application of the Breguet range equation in the following form:

$$
\begin{aligned}
& \text { MTOW }=\mathrm{OEW}+W_{\text {pay }}+W_{f} \\
& =\frac{\mathrm{OEW}+W_{\text {pay }}}{\left(1-\left(W_{\mathrm{cf}} / \mathrm{MTOW}\right)\right)} \exp \left(\frac{s g}{(L / D)_{\text {ref }}\left(X_{N, \text { ref }} / X_{N}\right) \mathrm{LCV} \eta_{o}}\right)
\end{aligned}
$$

This approach accounts for the fuel consumed during climb, $W_{\mathrm{cf}}$, calculated using potential energy arguments from Torenbeek [14]. The total mission fuel weight $W_{f}$ is then combined with the range and payload information to determine changes in fuel burn per passenger kilometer.

\section{Noise Modeling}

The engine thrust required during takeoff is determined from a force balance, assuming a small angle of attack and small climb angle:

$$
X_{N, \mathrm{TO}}=g \operatorname{MTOW}\left(\frac{1}{(L / D)_{\mathrm{TO}}}+\sin \left(\alpha_{\mathrm{TO}}\right)\right)
$$

The lift-to-drag ratio at takeoff is an input airframe parameter and is not equal to the value at climb altitude. At takeoff, airframe induced drag is dominant and changes in the nacelle drag and the drag ingested due to BLI are neglected by the model at this condition. Using the net thrust from Eq. (19), the operating point of the fan can be determined from Eqs. (2-5) and the fan characteristic (see [4]). This then enables the jet mixing noise and the fan rearward noise to be estimated using the methods described subsequently.

\section{Jet-Noise Model}

To predict jet-noise emission, the thermodynamic properties of the exhaust jet must be computed. With a known fan operating condition and engine geometry, the velocity, area, temperature, and density of the jet can be determined. Jet mixing noise is then predicted using a simplification of the Stone jet-noise model [15] (where OASPL is the overall sound pressure level):

$$
\begin{aligned}
& \text { OASPL }=10 \log _{10}\left(A_{j}\right)+10 \omega \log _{10}\left(\rho_{j}\right)+75 \log _{10}\left(V_{j}\right) \\
& \quad+50 \log _{10}\left(1-\frac{V_{\infty}}{V_{j}}\right)+C
\end{aligned}
$$

The applicability of this model to high-bypass-ratio engines and low flight velocities was investigated in some detail within the silent aircraft project, and some further details are given in [2]. The Stone model represented by Eq. (20), combined with flight corrections given in [16], was found to give the best results for the low ratios of jet velocity to flight speed used in the silent aircraft. For the technology assessment tool, the jet-noise model was only required to calculate differences between designs. For this purpose, the Stone model was expected to give accurate results, and the value of the constant $C$ in Eq. (20) does not need to be determined. To calculate the jet noise in $A$-weighted decibels (dBA), the OASPL is first converted into sound pressure levels (SPL) according to a reference jet-mixing-noise spectrum in [15]. The SPL at each frequency is then converted into $\mathrm{dBA}$ using the method in [17], and thus the change in peak dBA relative to a reference level is found. 


\section{Fan-Noise Model}

In the technology assessment method described in this paper, only rearward fan noise is evaluated. For aircraft configurations with an all-lifting wing, the rearward propagating broadband noise is usually dominant because forward engine noise can be shielded by the airframe, but this would not be true for other airframe and engine installations. The model for fan broadband noise is as follows:

$$
\begin{aligned}
& \mathrm{SPL}=20 \log _{10}\left(T_{0 \infty} \mathrm{FPR}^{(\gamma-1) / \eta_{f p} \gamma}\right)+10 \log _{10}(\dot{m}) \\
& +50 \log _{10}\left(U_{f}\right)+f\left(l_{\mathrm{ex}} / d_{f}\right)
\end{aligned}
$$

The first two terms are based on the fan-noise model in [18]. The third term is from Ginder and Newby [19] and considers the effect of tip speed on fan noise. The fourth term is a simple model for attenuation due to acoustic treatment, based on results from Law and Dowling [20]. The fan sound pressure levels are converted into dBA by scaling the characteristic frequency spectrum from [18] around the fan bladepassing frequency, BPF. To determine the $\mathrm{B} \overline{\mathrm{PF}}$ and the fan noise, the fan blade speed and number of blades are required.

\section{Aircraft Technology Study}

This section applies the technology assessment method described previously to investigate design tradeoffs between fuel burn and noise for the application of different technologies. It is often assumed that designing for low noise requires a compromise in fuel burn. The new method is a quick way to determine when there are such tradeoffs and to show the circumstances in which both low noise and low fuel burn are possible.

The focus of this study is on engine and installation technologies. However, the airframe layout, weight, and aerodynamic performance all have a fundamental impact on the propulsion system and therefore need to be included. Two types of airframe are considered: the conventional tube and wing and the novel all-lifting wing. The alllifting wing has greater potential for alternative engine installations because there is more space available at the back of the airframe. In this paper, all the characteristics used for the all-lifting wing are based on the airframe designed for the silent aircraft, SAX-40, described in [3].

Table 1 summarizes results from the technology assessment method for four configurations of airframe and engine, all with the same range and payload requirements. Design a is the reference conventional airframe with two podded turbofans. Design $b$ is the silent aircraft all-lifting-wing design, also fitted with podded engines. Designs $\mathrm{c}$ and $\mathrm{d}$ apply some of the engine and installation technologies that are examined later in this section. All of the all-liftingwing designs in the table apply 2025 technology estimates for the engine models and assume a variable-area exhaust nozzle.

\section{A. Engine Technologies}

\section{Ultrahigh-Bypass-Ratio Engines}

Over the last three decades, engine bypass ratios have been continuously increasing, with design FPRs decreasing accordingly. This has led to lower jet velocities, which has corresponded to benefits in reduced jet noise and increased propulsive efficiency. Moving to an even lower design FPR (ultrahigh-bypass-ratio engines) requires even larger fans that are heavier with greater nacelle drag. Figure $\underline{8}$ shows the variation in noise and fuel consumption as a function of design FPR for a nongeared podded turbofan, as predicted by the technology assessment tool. Each point on the plot represents a
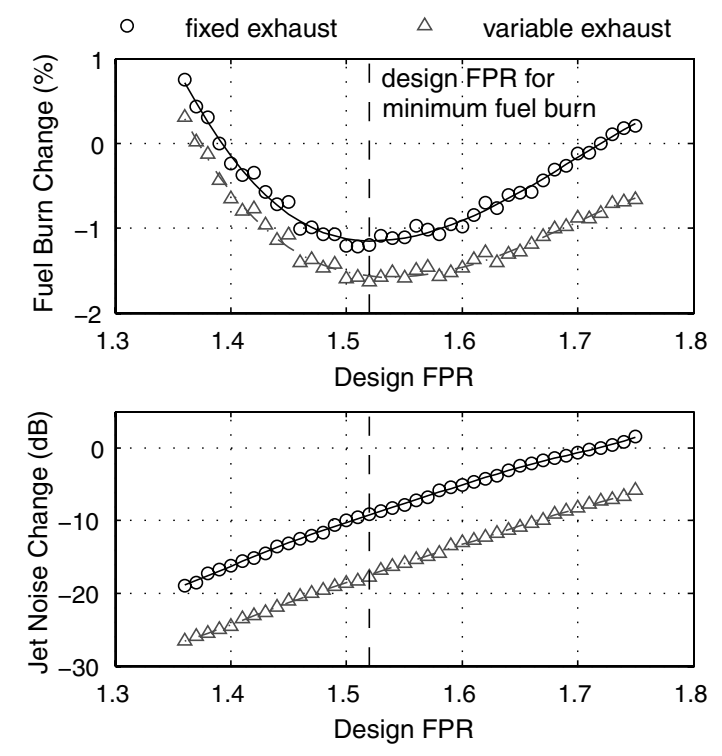

Fig. 8 Variation of jet noise and fuel consumption with design FPR.

different engine design, and all the designs were sized to power the same twin-engine conventional aircraft. As can be seen, engine noise is predicted to decrease monotonically with design FPR, but below a certain value of design FPR (calculated to be $\sim 1.52$ ) there is a tradeoff between noise emission and fuel burn. The latest turbofan designs are already close to this value of design FPR.

\section{Variable-Area Nozzle Exhaust}

The variable-area exhaust nozzle is a technology with potential for large reductions in jet noise. The idea is to increase the jet area at takeoff, thus reducing the FPR and the jet velocity [see Eqs. (2-4)]. Opening the exhaust nozzle also improves the stability of the fan at takeoff, which means that the FPR can be further reduced. At cruise and at top of climb, the nozzle area is set to be the same as for a fixednozzle design so that the fan efficiency can be maximized. For further details on the operation of a transonic fan with a variable-area exhaust, see $[\underline{4}, \underline{10}]$.

In Fig. 8 the variations of jet noise and fuel burn with design FPR are presented for engine designs with a variable exhaust nozzle. The nozzle area variation used is around $40 \%$ of the cruise nozzle area and this is the change required to maximize the fan-face Mach number at takeoff (see [4]). The technology assessment tool results show that at a design FPR of 1.52, the variable exhaust gives a significant jet-noise reduction $(\sim 8 \mathrm{dBA})$. To obtain this noise level with a fixed-nozzle engine, the design FPR would have to be reduced to a value of just below 1.4 , which is predicted to incur a fuel burn penalty of $\sim 1.5 \%$.

In addition to reducing jet noise, the variable-area nozzle slightly improves fuel consumption for a given design FPR. With a fixednozzle design, a fan is constrained to operate on a cruise working line that might not be precisely at peak efficiency, whereas a variable nozzle enables the operating condition to be corrected during flight, thus ensuring that the optimum efficiency is achieved. However, it is also possible that a variable-area nozzle leads to some noise sources increasing in magnitude. As an exhaust nozzle is opened, although the fan pressure ratio and jet velocity fall, the fan tip speed and axial flow velocity increase to maintain the same thrust. Thus, a tradeoff can arise between fan source noise and jet noise, which demands

Table 1 Sample results from the assessment method for key aircraft configurations

\begin{tabular}{ccccccccccc}
\hline \hline Design & Airframe & Installation & MTOW kg & Cruise $L / D$ & Design FPR & $n_{f}$ & $l_{\text {ex }} / d_{f}$ & $d_{f}, \mathrm{~m}$ & $\Delta$ Noise dBA & $\Delta$ fuel burn, $\%$ \\
\hline a & 2005 Tube and wing & Podded & 184,612 & 21.9 & 1.60 & 2 & 0.25 & 2.26 & 0 & 0 \\
b & 2025 all-lifting wing & Podded & 152,320 & 24.0 & 1.52 & 3 & 0.25 & 1.95 & -14.8 & -32.0 \\
c & 2025 all-lifting wing & BLD & 152,320 & 24.0 & 1.52 & 3 & 2.00 & 2.03 & -21.0 & -23.6 \\
$\mathrm{~d}$ & 2025 all-lifting wing & BLI & 152,320 & 24.0 & 1.52 & 9 & 3.00 & 1.13 & -22.7 & -33.7 \\
\hline \hline
\end{tabular}


careful attention. Within [4] it is shown that by setting the variablearea nozzle to minimize the incidence angles onto the fan rotor blades, the fan efficiency at takeoff can be improved, and it should be possible to simultaneously reduce both jet noise and fan source noise.

\section{B. Integration Technologies}

Almost all current passenger aircraft use podded installations in which the engines are mounted externally to the airframe on pylons and housed within separate nacelles. This approach requires less complex design, because the airframe and engine performances can be decoupled, and there are several advantages in terms of the engine maintenance, operability, and safety. However, future aircraft designs are likely to revisit other forms of engine installation because they have the potential to significantly reduce noise and fuel consumption.

The technology assessment method described in this paper can analyze two types of engine installations in which the engines are embedded within the airframe structure: BLI and BLD. Embedded engine installations experience efficiency losses due to complicated inlet geometries and duct secondary flows. These affect performance through reductions in the inlet and exhaust pressure recoveries, $P_{\text {in }}$ and $\mathrm{PR}_{\mathrm{ex}}$. However, embedded engines are potentially lower weight, as there is no pylon structure and they can have reduced nacelle surface area. They have greater flexibility in the arrangement and number of engines that can be used and there is also increased scope for noise reduction through airframe shielding and greater acoustic liners.

\section{Extended Acoustic Liners}

Acoustic liners are applied to reduce engine noise propagation out of the intake and exhaust. Although improved acoustic liners are under constant development, the total noise reduction that can be achieved is limited by the area available for liner application within the intake and exhaust ducts. Extended exhaust cowls are sometimes used to increase the surface area available for attenuation devices, but a fuel burn penalty is incurred due to increased frictional losses. This tradeoff between noise suppression and engine performance is demonstrated in Fig. 9, which shows results from the method for three types of engine installations applied to an all-lifting-wing airframe. Each curve represents a series of designs with varying lengths of acoustically treated engine exhaust duct. The plot shows that as duct length is increased, the noise benefits become progressively smaller and the fuel burn impact increases. In other words, the tradeoff between noise and fuel burn worsens as the duct lengthens.

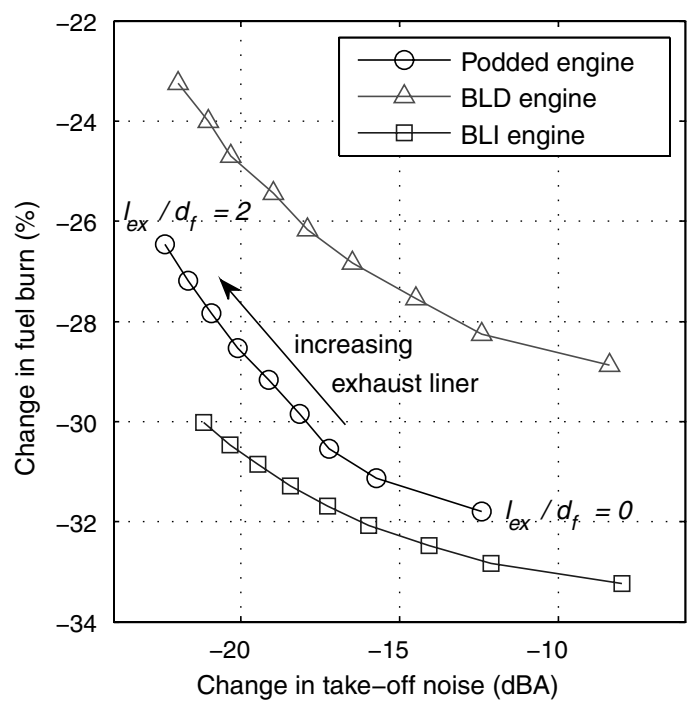

Fig. 9 Noise and fuel burn tradeoffs for varying lengths of acoustic liner in the engine exhaust.

\section{Boundary-Layer Ingestion and Distributed Propulsion}

Figure 10 illustrates the variations in noise and fuel burn for a selection of engine installations applied to an all-lifting-wing airframe. Each curve represents a series of designs generated by varying the engine design FPR. Marked on the plot are designs b, c, and d, as detailed in Table 1 . For the podded and BLD systems with three engine fans, a tradeoff exists between noise and fuel burn. Essentially, although the BLD configuration enables significant noise reduction, the additional losses in the inlet and exhaust lead to a high fuel burn penalty. It is only when BLI is combined with distributed propulsion that both lower noise and significantly better fuel economy are achieved relative to a conventional installation. With this configuration, the higher number of engine fans leads to reduced overall weight of the propulsion system (see [10]) and lower nacelle drag [Eq. (7)]. BLI gives greater fuel burn benefit when there are more engine fans, because a greater proportion of the airframe boundary layer can be ingested [Eq. ( $\underline{8})]$. The smaller fans are also quieter, because their BPF is higher and the exhaust acoustic liners are more effective.

\section{Application of the Method to the Silent Aircraft}

The technology assessment method was applied to a variety of aircraft configurations to determine the relative value of technologies individually and in combination. The results of the analysis can be presented as a chart that shows the effect of adopting technologies one at a time. This chart is described as a mountain chart, as it shows a series of results for a discrete progression of designs of increasing complexity. Figure 11 is an example for a sequence of designs beginning with a current-production aircraft and culminating with the advanced silent aircraft conceptual design.

In Fig. 11 noise and fuel consumption are evaluated for each intermediate configuration relative to a 2005 reference aircraft designed for the same mission. Technologies are applied in order of increasing risk, and error bars indicate the uncertainty associated with the models. To determine the error bars, the uncertainties on each input parameter were estimated and, when available, uncertainties in the noise and weight models were taken from literature. The assessment tool was then run with various combinations of these uncertainties to give a range of results for the overall changes in noise and fuel burn. The ranges of possible results tend to increase as more design changes are introduced, which is why the error bars tend to get larger toward the right of the figure.

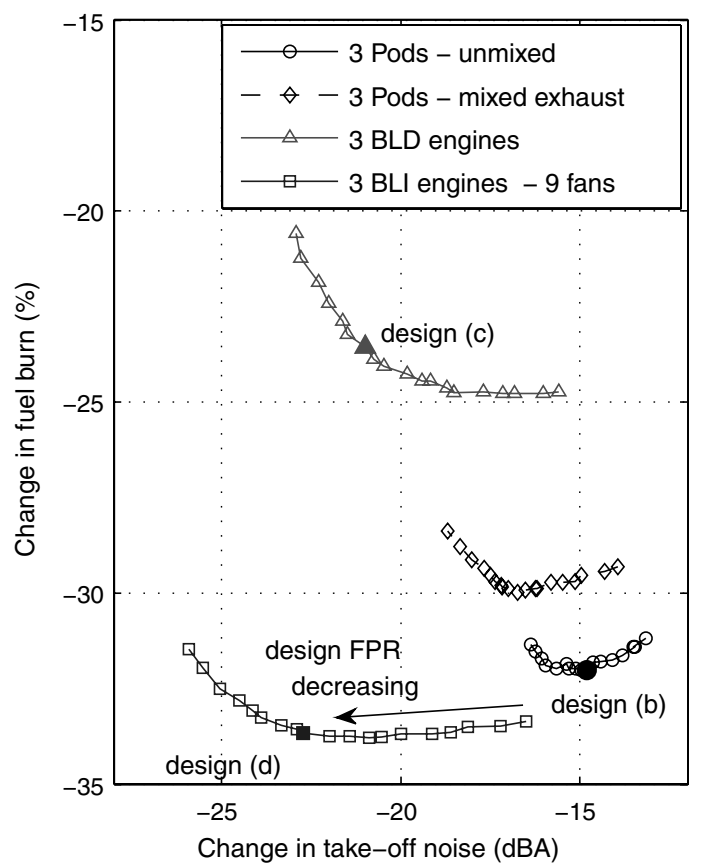

Fig. 10 Tradeoffs for various engine installations, each applied to an all-lifting wing. 


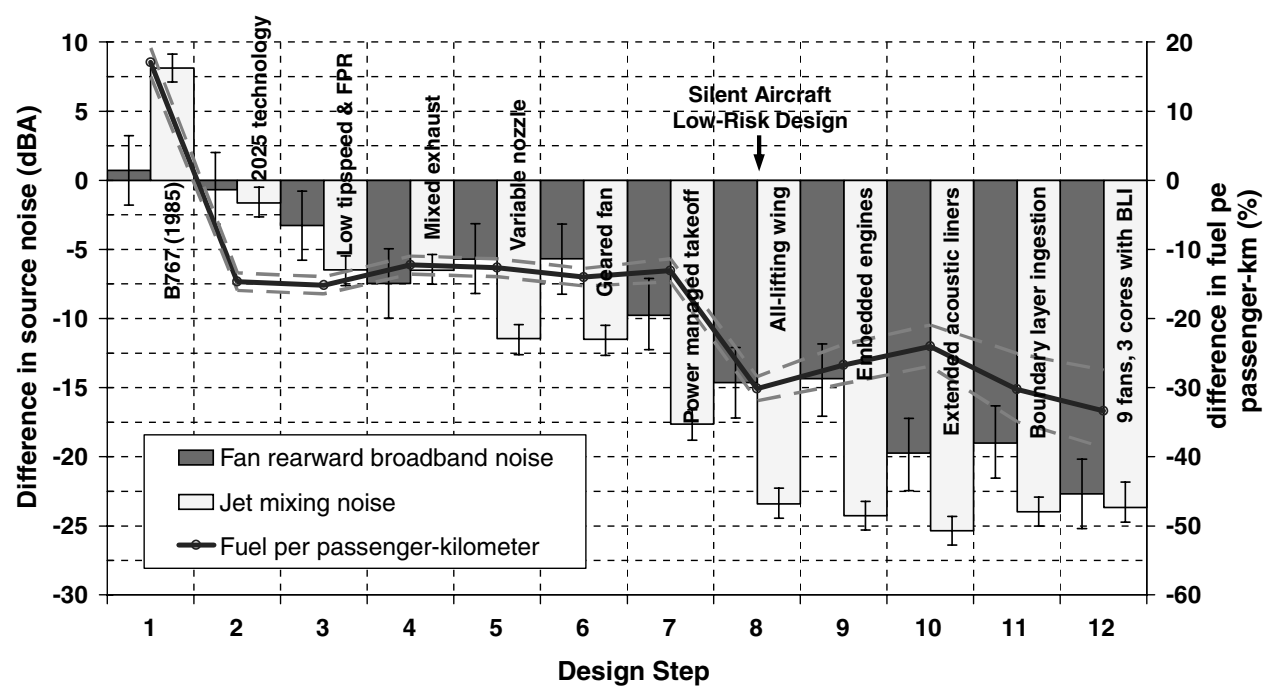

Fig. 11 The Silent Aircraft mountain chart for engine noise and fuel burn.

Design 1 in Fig. 11 is based on the Boeing 767, which uses 1980s engine and airframe technology, as detailed in [13]. Expected improvements in engine component efficiencies, turbine temperatures, and airframe weight are applied to design 2, creating a large fuel burn reduction. Design 3 features reduced fan pressure ratio and tip speed, leading to reductions in jet and fan noise, respectively. The variable-area nozzle is applied to design 5 , reducing jet noise during takeoff by $5 \mathrm{~dB}$ and fuel burn during cruise by $0.4 \%$. The engine for design 6 is a geared fan, with a lighter and more efficient turbine. In design 7, the number of engines is increased from two to three to enable a low-power takeoff, reducing both jet and fan noise substantially.

Dramatic performance effects are seen in the shift of airframe for design 8 . The all-lifting wing delivers a step change of $-17 \%$ in fuel burn as well as reductions in all sources of noise at takeoff. The three engines of design 9 are embedded into the airframe, and for design 10 the exhaust ducts are stretched even farther for $5 \mathrm{~dB}$ fan-noise attenuation. The inlets employed by design 11 ingest the incoming boundary layer, giving a fuel burn benefit that counters the effect of the long exhaust ducts. Finally, design 12 combines BLI with distributed propulsion via a common core system of 9 fans and 3 gas generators.

Some key results from the mountains chart analysis are summarized in Table 2. Note that, similar to the mountain chart, the changes in the table are the incremental effects, and so the total impact of incorporating several technologies is the sum of the results. Table 2 shows that with a conventional tube-and-wing aircraft, further advances in engine technology and lightweight materials will lead to a significant fuel burn reduction, and with a variable exhaust nozzle and an optimized departure, a large rearward noise benefit can also be obtained. However, the results demonstrate that the alllifting-wing airframe is expected to provide much lower engine noise as well as delivering a dramatic fuel burn reduction. The engine noise reduction arises as a result of the improved low-speed aerodynamics

Table 2 Summary of the noise and fuel burn effects of the principal silent aircraft technologies

\begin{tabular}{lcc}
\hline \hline Technology & $\begin{array}{c}\text { Change in fuel burn } \\
\text { per passenger } \\
\text { kilometer, } \%\end{array}$ & $\begin{array}{c}\text { Change in } \\
\text { engine takeoff } \\
\text { noise, dBA }\end{array}$ \\
\hline 2025 materials and design & -15.0 & -2.2 \\
Variable-area nozzle & -0.4 & -4.9 \\
Optimized departure & 0.0 & -6.4 \\
All-lifting-wing airframe & -17.0 & -6.0 \\
Embedded engines & +3.4 & -4.9 \\
Boundary-layer ingestion with & -9.3 & -3.0 \\
$\quad$ distributed propulsion & & \\
\hline \hline
\end{tabular}

of the airframe that enable a significant thrust reduction and a more optimum departure profile. The all-lifting-wing airframe also provides shielding of the forward engine noise. Because the forwardnoise components are not estimated by the technology assessment method, the overall noise improvements possible with an all-lifting wing are expected to be significantly higher than indicated by these results, as shown in [2].

Embedded engines when combined with both boundary-layer ingestion and distributed propulsion can enable further reductions in overall noise and fuel burn. For the silent aircraft final design, the multiple fan configuration was crucial for enabling exhaust ducts with very large length-to-diameter ratios. This led to extensive optimized acoustic liners that were highly effective at eliminating rearward fan noise. However, the net gains provided by this complex engine configuration are smaller than for other technologies and it was considered as high-risk.

\section{Silent Aircraft Low-Risk Design}

Based on the results presented in the mountain chart (Fig. 11) and the summary given in Table 2, it was concluded that a lower-risk design of silent aircraft should have the following features: 1) alllifting-wing airframe, 2) podded engines with variable-area exhaust nozzles, 3) mixed exhaust with extensive acoustic liners, and 4) power-managed takeoff.

To determine the viability of such a design concept, the SAX aircraft design methodology of Hileman et al. [3] was used to create a lower-risk silent aircraft design concept, which was designated SAX-L/R1, pictured in Fig. 12. This aircraft design concept used the SAX-40 centerbody and three podded engines, and the outer-wing configuration was optimized to yield a balanced aircraft configuration. The SAX-L/R1 conceptual design was chosen from a Pareto front of aircraft designs that had variation in the outer-wing configuration. To maintain minimum noise, the chosen design had the same stall speed as the SAX-40 design. Figure 13 depicts the planform shapes and engine placements for the $\mathrm{SAX}-40$ and SAX-L/R1 aircraft concepts, and Table 3 presents some key parameters that define the two designs. To maintain the stall speed, the planform area increased and the outer-wing placement shifted aft to maintain aircraft trim

The fuel efficiency for the SAX-L/R1 aircraft concept decreased to 113 passenger miles per gallon (relative to the 124 passenger miles per gallon for the SAX-40 design) because of an increase in nacelle drag, installed engine weight, and planform area; the lack of BLI also led to an increase in thrust-specific fuel consumption. The noise increased during takeoff to be $65 \mathrm{dBA}$ at the airport perimeter because of increased fan rearward noise (relative to $63 \mathrm{dBA}$ for the SAX-40 design). This increase is due to the use of shorter engine liners and an increase in takeoff thrust to accommodate the increased 


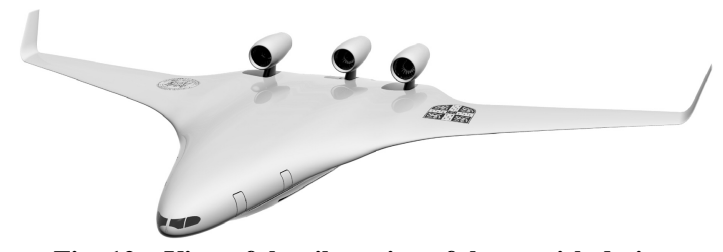

Fig. 12 View of the silent aircraft lower-risk design.

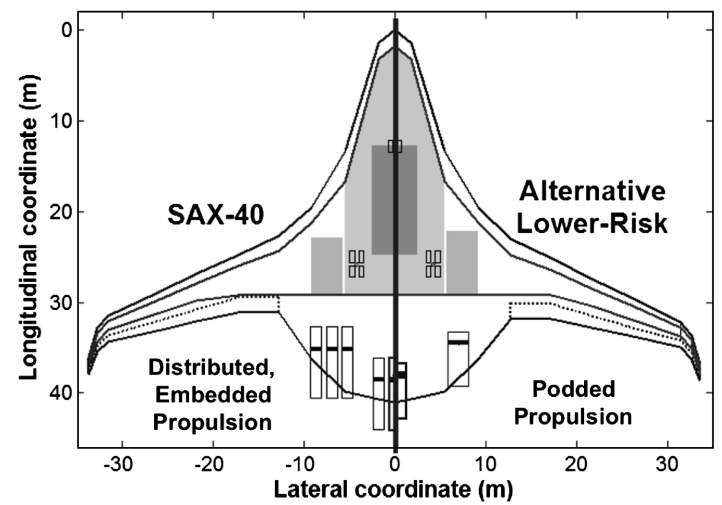

Fig. 13 Planform comparison for the SAX-40 and SAX-L/R1 aircraft concepts.

weight. The approach noise was not analyzed to the same depth as the takeoff noise, but a preliminary examination suggested the noise would increase to $70 \mathrm{dBA}$. With these perimeter noise estimates, the cumulative noise for the SAX-L/R1 design would be roughly $225 \mathrm{EPNdB}$ (effective perceived noise in decibels), which is $15 \mathrm{EPNdB}$ above the SAX-40 conceptual design; however, this is 60 EPNdB below the current International Civil Aviation Organization stage 4 requirement.

\section{Conclusions}

An integrated method has been developed to rapidly investigate the impact of new technologies on the fuel consumption and engine noise of an aircraft design. This tool uses a new approach to combine the weight, drag, and efficiency differences of new technologies to calculate the impact on overall fuel burn. Simple offdesign calculations are also completed to determine the effect of new technologies on noise.

Through varying engine and installation design parameters, such as the design fan pressure ratio or exhaust duct length-to-diameter ratio, the tradeoffs between engine noise and aircraft fuel consumption have been examined with the new method. These studies indicate that some combinations of technologies can enable both reduced noise and reduced fuel burn.

The method has been used to assess the technologies considered for the Silent Aircraft Initiative. The results allow these technologies to be ranked in terms of the benefits they deliver to fuel burn and noise reduction. The method has also enabled an aircraft concept to be identified that eliminates the need for the high-risk propulsion technologies used in the final silent aircraft design. This new lowerrisk aircraft features an all-lifting-wing airframe, podded engines with variable-area exhaust nozzles, and a power-managed takeoff procedure. The design of this aircraft has been completed and compared with the final silent aircraft configuration. The results show that although this lower-risk configuration is expected to be marginally louder and less fuel-efficient than the final silent aircraft design, it would still represent a dramatic improvement relative to current aircraft.

\section{Appendix A: Bypass Efficiency of a Combined Fan and Installation System}

Figures $\mathrm{A} 1$ and $\mathrm{A} 2$ show the station numbering and the enthalpyentropy diagram for the flow through the bypass system of a turbofan engine. The bypass efficiency is an efficiency measure for the fan, bypass duct, and engine installation. It relates the kinetic energy added to the bypass flow to the mechanical energy input, which can be expressed as follows:

$$
\eta_{\text {byp }}=\frac{\Delta K E_{\text {byp }}}{P_{\text {byp }}}=\frac{1 / 2\left(V_{j}^{2}-V_{0}^{2}\right)}{h_{013}-h_{01}}=1-\frac{T_{j}-T_{a}}{T_{013}-T_{01}}
$$

To determine this efficiency, $T_{j}-T_{a}$ is required for the system. This can be determined by considering the separate entropy increases through the fan and installation components. Through the fan, the entropy change can be determined by considering the entropy change required to move from point $13 f \rightarrow 13$ at constant pressure:

$$
T_{013 f}\left(s_{13}-s_{2}\right) \approx h_{013}-h_{013 f}=C_{p} T_{01}\left(\frac{T_{013}}{T_{01}}-\operatorname{FPR}^{(\gamma-1) / \gamma}\right)
$$

This can be combined with the definition of fan isentropic efficiency $\eta_{f}$ to give

$$
\left(s_{13}-s_{2}\right) \approx c_{p}\left(\frac{\left(1-\eta_{f}\right)\left(\mathrm{FPR}^{(\gamma-1) / \gamma}-1\right)}{\eta_{f} \operatorname{FPR}^{(\gamma-1) / \gamma}}\right)
$$

Through the inlet duct, the entropy change can be determined by using the fact that $h_{02}=h_{01}$ and

$$
\left(s_{2}-s_{a}\right)=-R \ln \left(p_{02} / p_{01}\right)=-R \ln \left(\mathrm{PR}_{\mathrm{in}}\right)
$$

Similarly for the exit duct, $h_{018}=h_{013}$ and

$$
\left(s_{j}-s_{13}\right)=-R \ln \left(\mathrm{PR}_{\mathrm{ex}}\right)
$$

The preceding expressions can then be combined to find the overall bypass efficiency:

$$
\begin{aligned}
\eta_{\text {byp }} & =1-\frac{T_{j}-T_{a}}{T_{013}-T_{01}} \\
& \approx 1-\frac{T_{a}}{T_{01}} \frac{\left\lfloor\left(s_{2}-s_{a}\right)+\left(s_{13}-s_{2}\right)+\left(s_{j}-s_{13}\right)\right\rfloor}{\left(T_{013} / T_{01}-1\right) c_{p}}
\end{aligned}
$$

Table 3 Comparison of key parameters for the SAX-40 and SAX-L/R1 aircraft concepts

\begin{tabular}{lcc}
\hline \hline & SAX-40 & SAX-L/R1 \\
\hline Engine architecture & BLI: 3 cores driving 9 fans & Podded: 3 cores driving 3 fans \\
Mission & \multicolumn{2}{c}{$5000 \mathrm{~nm}, 215$ passengers } \\
Cruise $M L / D$ & 20.1 & 19.8 \\
MTOW, $\mathrm{kg}$ & 150,847 & 157,814 \\
OEW, $\mathrm{kg}$ & 94,193 & 97,318 \\
Engine installed weight, $\mathrm{kg}$ & 16,697 & 20,697 \\
Planform area, $\mathrm{m}^{2}$ & 835.9 & 847.2 \\
Fan diameter $d_{f}, \mathrm{~m}$ & 1.20 & 2.20 \\
Exhaust liner length $l_{\mathrm{ex}} / d_{f}$ & 4.0 & 1.9 \\
Fuel efficiency $($ passenger miles/gal) & 124 & 113 \\
Airport perimeter noise $(\mathrm{dBA})$ takeoff/sideline/approach & $62 / 62 / 61$ & $65 / 65 \sim 70$ \\
\hline \hline
\end{tabular}




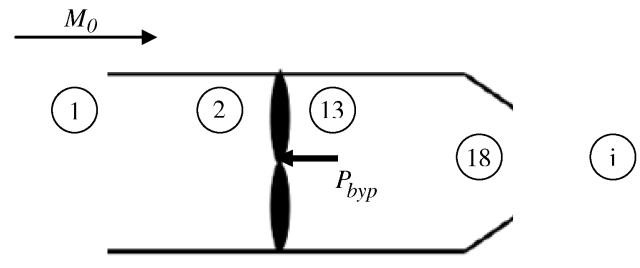

Fig. A1 Station numbering for the bypass system.

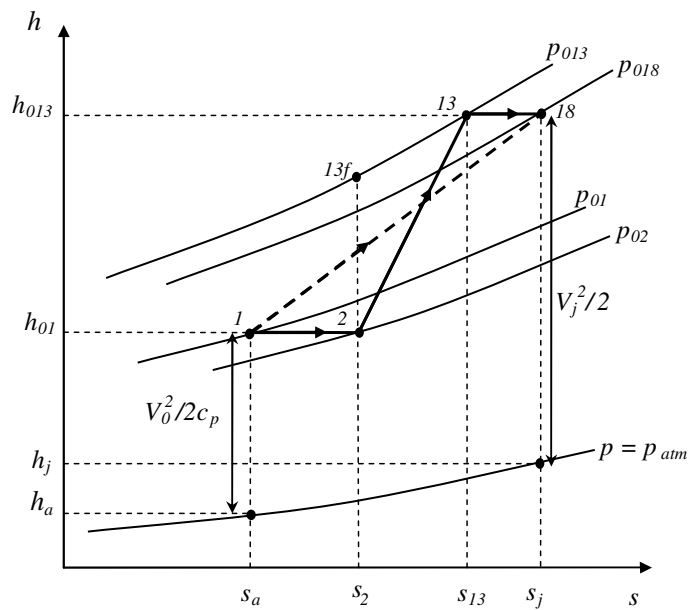

Fig. A2 Station numbering and enthalpy-entropy diagram for a fan within an engine installation.

Substituting in Eqs. (A2-A4) and simplifying gives

$$
\eta_{\text {byp }} \approx 1-\frac{T_{a}}{T_{01}}\left[\frac{\left(1-\eta_{f}\right)}{\operatorname{FPR}^{(\gamma-1) / \gamma}}-\frac{\ln \left(\mathrm{PR}_{\text {in }} \mathrm{PR}_{\mathrm{ex}}\right) \eta_{f}(\gamma-1) / \gamma}{\left(\mathrm{FPR}^{(\gamma-1) / \gamma}-1\right)}\right]
$$

\section{Acknowledgments}

The authors would like to acknowledge the Cambridge-MIT Institute and the Silent Aircraft Initiative project for the support of this research. They would also like to thank all the members of the silent aircraft team who have contributed to the work that made this paper possible. Particular thanks to Daniel Crichton, Elena de la Rosa Blanco, Zoltan Spakovszky, Ed Greitzer, Tom Hynes, Tom Law, Vahid Madani, Matthew Sargeant, and Angelique Plas.

\section{References}

[1] "European Aeronautics: A Vision for 2020," European Commission, Luxembourg Office for Official Publications of the European Communities, Jan. 2001.

[2] Hileman, J. I., Crichton, D., de la Rosa Blanco, E., and Law, T. R., "Design and Operation for Ultra Low Noise Takeoff," 45th AIAA Aerospace Sciences Meeting, AIAA Paper 2007-0456, Reno, NV,
Jan. 2007.

[3] Hileman, J. I., Spakovszky, Z. S., Drela, M., Sargeant, M. A., Liebeck, R. H., Roman, D., and Wakayama, S., "Airframe Design for the Silent Aircraft," 45th AIAA Aerospace Sciences Meeting, AIAA Paper 20070453, Reno, NV, Jan. 2007.

[4] Crichton, D., Xu, L., and Hall, C. A., "Preliminary Fan Design for a Silent Aircraft," Journal of Turbomachinery, Vol. 129, No. 1, Jan. 2007, pp. 184-191. doi:10.1115/1.2372779

[5] Shevell, R. S., Fundamentals of Flight, Prentice-Hall, Upper Saddle River, NJ, 1989.

[6] Plas, A. P., Madani, V., Sargeant, M. A., Greitzer, E. M., Hall, C. A., and Hynes, T. P., "Performance of a Boundary Layer Ingesting (BLI) Propulsion System," the 45th Aerospace Sciences Meeting and Exhibit Conference, AIAA Paper 2007-0450, Reno, NV, Jan. 2007.

[7] Cumpsty, N. A., Jet Propulsion: A Simple Guide to the Aerodynamic and Thermodynamic Design and Performance of Jet Engines, Cambridge Univ. Press, Cambridge, England, U.K.2003.

[8] Hill, P., and Peterson, C., Mechanics and Thermodynamics of Propulsion, 2nd ed., Addison Wesley Longman, Reading, MA, 1992.

[9] GasTurb, Software Package, Ver. 10, Kurzke, J., Dachau, Germany, 2004, available online at www.gasturb.de [retrieved Feb. 2009].

[10] Hall, C. A., and Crichton, D., "Engine Design Studies for a Silent Aircraft," Journal of Turbomachinery, Vol. 129, No. 3, 2007, pp. 479_ 487. doi:10.1115/1.2472398

[11] Raymer, D., Aircraft Design: A Conceptual Approach, AIAA, Reston, VA, 1999.

[12] de la Rosa Blanco, E., Crichton, D., and Hall, C., "Challenges in the Silent Aircraft Engine Design," the 45th Aerospace Sciences Meeting and Exhibit Conference, AIAA Paper 2007-0454, Reno, NV, Jan. 2007.

[13] Jenkinson, L., Simpkin, P., and Rhodes, D., Civil Jet Aircraft Design: Data Sets [online database], Butterworth-Heinemann, 2001, http:// www.elsevierdirect.com/companions/9780340741528/appendices/ default.htm [retrieved Feb. 2009].

[14] Torenbeek, E., "Cruise Performance and Range Prediction Reconsidered," Progress in Aerospace Sciences, Vol. 33, Nos. 5-6, 1997, pp. 285-321. doi:10.1016/S0376-0421(96)00007-3

[15] Stone, J. R., and Montegani, F. J., "An Improved Prediction Method for the Noise Generated in Flight by Circular Jets," NASA TM-81470, 1980.

[16] Low, J. K. C., "Ultra-High Bypass Ratio Jet Noise,” NASA CR-195394, 1994.

[17] "An Introduction to Aircraft Noise," ESDU International, Data Item ESDU 02020, London, Dec. 2002.

[18] "Prediction of Noise Generated by Fans and Compressors in Turbojet and Turbofan Engines," ESDU International, Data Item ESDU 98008, London, 2003.

[19] Ginder, R., and Newby, D., "An Improved Correlation for the Broadband Noise of High-Speed Fans," Journal of Aircraft, Vol. 14, No. 9, 1977, pp. 844-849. doi: $10.2514 / 3.58864$

[20] Law, T., and Dowling, A., "Optimization of Traditional and Blown Liners for a Silent Aircraft," AIAA Paper 2006-2525. 